\title{
Digital Image Analysis of Ki-67 Stained Tissue Microarrays and Recurrence in Tamoxifen-Treated Breast Cancer Patients
}

This article was published in the following Dove Press journal: Clinical Epidemiology

\author{
Nina Gran Egeland ${ }^{1,2}$ \\ Kristin Jonsdottir (iD) \\ Kristina Lystlund Lauridsen ${ }^{3}$ \\ Ivar Skaland (D) ' \\ Cathrine $\mathrm{F}$ Hjorth (D) ${ }^{4}$ \\ Einar G Gudlaugsson (iD) \\ Stephen Hamilton-Dutoit (iD ${ }^{3}$ \\ Timothy L Lash (iD) \\ Deirdre Cronin-Fenton (D) $4, *$ \\ Emiel AM Janssen (iD) ${ }^{1,2, *}$ \\ 'Department of Pathology, Stavanger \\ University Hospital, Stavanger, Norway; \\ ${ }^{2}$ Department of Chemistry, Bioscience \\ and Environmental Engineering, \\ University of Stavanger, Stavanger, \\ Norway; ${ }^{3}$ Institute of Pathology, Aarhus \\ University Hospital, Aarhus, Denmark; \\ ${ }^{4}$ Department of Clinical Epidemiology, \\ Aarhus University Hospital, Aarhus, \\ Denmark; ${ }^{5}$ Department of Epidemiology, \\ Rollins School of Public Health and \\ Winship Cancer Institute, Emory \\ University, Atlanta, GA, USA
}

*These authors contributed equally to this work
Correspondence: Nina Gran Egeland Department of Pathology, Stavanger University Hospital, Box 8100, Stavanger 4068, Norway

Tel +4792425622

Email nina.gran.egeland@sus.no
Purpose: The proliferation marker Ki-67 has been used as a prognostic marker to separate low- and high-risk breast cancer subtypes and guide treatment decisions for adjuvant chemotherapy. The association of Ki-67 with response to tamoxifen therapy is unclear. Highthroughput automated scoring of Ki-67 might enable standardization of quantification and definition of clinical cut-off values. We hypothesized that digital image analysis (DIA) of Ki67 can be used to evaluate proliferation in breast cancer tumors, and that Ki-67 may be associated with tamoxifen resistance in early-stage breast cancer.

Patients and Methods: Here, we apply DIA technology from Visiopharm using a custom designed algorithm for quantifying the expression of $\mathrm{Ki}-67$, in a case-control study nested in the Danish Breast Cancer Group clinical database, consisting of stages I, II, or III breast cancer patients of 35-69 years of age, diagnosed during 1985-2001, in the Jutland peninsula, Denmark. We assessed DIA-Ki-67 score on tissue microarrays (TMAs) from breast cancer patients in a case-control study including 541 ER-positive and 300 ER-negative recurrent cases and their non-recurrent controls, matched on ER-status, cancer stage, menopausal status, year of diagnosis, and county of residence. We used logistic regression to estimate odds ratios and associated $95 \%$ confidence intervals to determine the association of Ki-67 expression with recurrence risk, adjusting for matching factors, chemotherapy, type of surgery, receipt of radiation therapy, age category, and comorbidity.

Results: Ki-67 was not associated with increased risk of recurrence in tamoxifen-treated patients $(\mathrm{ORadj}=0.72,95 \% \mathrm{CI} 0.54,0.96)$ or ER-negative patients $(\mathrm{ORadj}=0.85,95 \% \mathrm{CI}$ $0.54,1.34)$.

Conclusion: Our findings suggest that Ki-67 digital image analysis in TMAs is not associated with increased risk of recurrence among tamoxifen-treated ER-positive breast cancer or ER-negative breast cancer patients. Overall, our findings do not support an increased risk of recurrence associated with $\mathrm{Ki}-67$ expression.

Keywords: breast cancer, tamoxifen, proliferation, Ki-67, recurrence risk, tissue microarray, TMA, digital image analysis, DIA

\section{Introduction}

In spite of the relatively good prognosis for early-stage breast cancer, studies with as long as 20 years of follow-up suggest that the risk of recurrence remains consistently elevated after diagnosis. ${ }^{1,2}$ Around $70 \%$ of breast cancers are estrogen receptor (ER) positive $\left(^{+}\right)$. These patients are candidates for receiving endocrine therapy, which reduces the five-year risk of recurrence by about one-half. ${ }^{3}$ Tamoxifen is an ER modulator that selectively binds to the ER and blocks its 
ligand estradiol, thereby preventing ER activation and downstream tumor cell proliferation. ${ }^{4,5}$ Guidelines recommend tamoxifen as treatment for premenopausal $\mathrm{ER}^{+}$ patients, and is an important alternative and/or sequential treatment in postmenopausal patients. The tamoxifen treatment regimen has recently been extended from five to 10 years. ${ }^{6}$ Unfortunately, as many as $30 \%$ of breast cancer patients are, or become, resistant to the drug, either de novo or by acquired resistance, ${ }^{7,9}$ resulting in recurrence of disease. Furthermore, up to one-half of all patients stop taking their medication because of adverse side effects or for other reasons. ${ }^{10,12}$

$\mathrm{Ki}-67$ immunostaining is used as a marker of proliferation and has a well-documented prognostic value in breast cancer. $^{13,16}$ Together with histological grade, Ki-67 proliferation index can be used as a surrogate marker to separate low-risk Luminal A subtype (i.e. low proliferation, low grade, hormone receptor $(\mathrm{HR})^{+}$, human epidermal growth factor-receptor 2 (HER2) negative ( ) from the higher risk Luminal B subtype (i.e. high proliferation, high grade, $\left.\mathrm{HR}^{+-} / \mathrm{HER}^{+}{ }^{+}\right)^{17}$ In this way, proliferation can be used to guide treatment decisions regarding the use of adjuvant chemotherapy. ${ }^{18}$ Changes in Ki-67 expression in tumors following short-term neoadjuvant endocrine therapy have also been suggested as a marker of treatment efficacy; thus, breast cancer patients with tumors with high Ki-67 expression after treatment showed lower recurrence-free survival. ${ }^{19}$ The association of pre-treatment Ki-67 proliferation index with recurrence risk among women treated with tamoxifen therapy is, however, unclear. In the NSABP B-14 trial, among 16 cancer-related genes examined, MKI-67 gene expression of Ki-67 was not associated with the effectiveness of adjuvant tamoxifen treatment. ${ }^{20}$ A second randomized trial including 564 premenopausal women reported a more complex relationship between $\mathrm{Ki}$ 67 index and tamoxifen response; patients whose tumors showed either high or low Ki-67 levels benefitted more from tamoxifen compared with patients whose tumors had intermediate levels of Ki-67 expression. ${ }^{21}$ As such, further evidence is needed on the potential association between $\mathrm{Ki}-67$ value and tamoxifen therapy.

Scoring Ki-67 on tissue sections is challenging, not least because of a lack of standardized methods for performing, scoring and interpreting Ki-67 immunohistochemistry (IHC). ${ }^{22} \mathrm{Ki}-67$ is traditionally evaluated visually with a standard microscope rather than by using digital image analysis (DIA). As a result, the reproducibility varies. There is no international consensus regarding scoring methods or the most clinically relevant cut-off, although until recently, a cut-off value of 30\% was recommended by the Norwegian Breast Cancer Group. ${ }^{23}$ Compared with standard visual scoring of Ki-67, DIA offers a more objective, rapid and more reproducible method to determine the fraction of proliferating cells. ${ }^{16}$ We hypothesized that DIA of Ki-67 stained sections can be used to efficiently evaluate proliferation in breast cancer tumor specimens; we applied this methodology to investigate the potential association of the $\mathrm{Ki}-67$ index with a response to tamoxifen therapy.

\section{Patients and Methods}

\section{Study Population}

The source and study populations have been previously described. ${ }^{24}$ In brief, the source population consisted of all women $(n=11,252)$ aged 35 to 69 living in the Jutland Peninsula in Denmark, diagnosed with non-metastatic (stages I-III) invasive breast cancer between 1985 and 2001, and registered in the clinical database of The Danish Breast Cancer Group (DBCG) Registry. ${ }^{25}$ The Jutland Breast Cancer Recurrence Biobank contains tumor sections, DNA/RNA, tissue microarrays (TMAs) and clinicopathological data. Derived from this biobank, the study population consisted of $541 \mathrm{ER}^{+}$breast cancer patients treated $\geq 1$ year with Tamoxifen ${ }^{\circledR}$ (grouped ER ${ }^{+}$/ $\mathrm{Tam}^{+}$) with recurrence and their 541 matched controls without recurrence, together with 300 ER-negative $\left(\mathrm{ER}^{-}\right)$ non-tamoxifen-treated (grouped $\mathrm{ER}^{-} / \mathrm{Tam}^{-}$) breast cancer patients with recurrence and their 300 matched controls without recurrence. An overview of the study design is shown in Figure 1. We sought to evaluate any association between Ki-67 score, as measured using the DIA-Ki-67 score, and breast cancer recurrence among women with estrogen receptor-positive and -negative breast cancer, treated with and without tamoxifen, respectively. Patients not meeting the inclusion criteria were excluded. Controls were matched to cases according to group $\left(\mathrm{ER}^{+} / \mathrm{Tam}^{+}\right.$or $\mathrm{ER}^{-} / \mathrm{Tam}^{-}$), year of diagnosis, derived UICC (Union for International Cancer Control) I-III cancer stage, menopausal status, and county of residence at the time of diagnosis. Controls were sampled using incidence density sampling whereby controls had to be alive and at risk of breast cancer recurrence on the date their corresponding case recurred. ${ }^{26}$ Without replacement, controls were selected from members of the source population, who were not diagnosed with a breast cancer recurrence or contralateral 


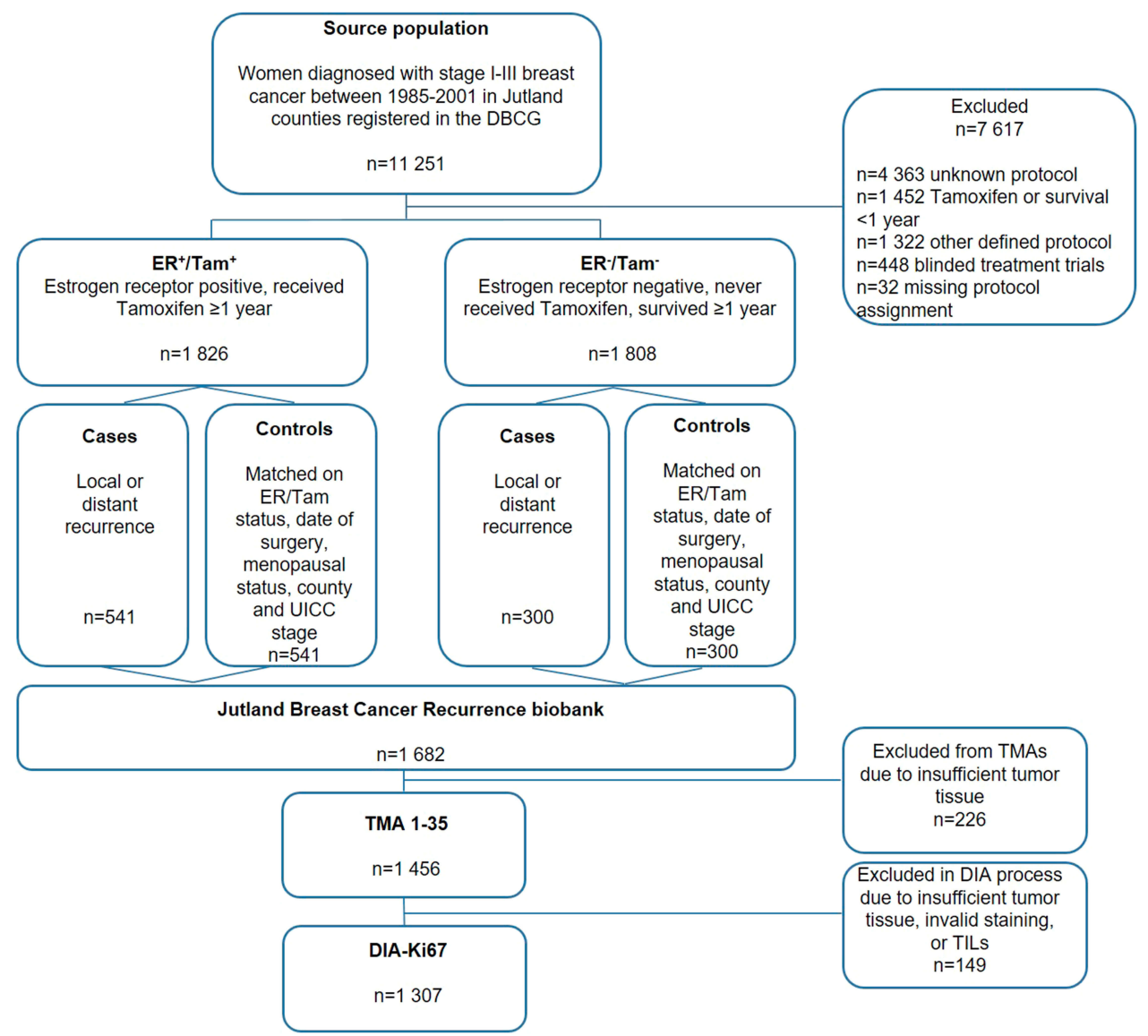

Figure I Study design.

Notes: The source population consisted of all female residents aged 35-69 of Denmark's Jutland Peninsula between I985 and $200 \mathrm{I}$, who were diagnosed with nonmetastatic breast cancer. Two-thirds of the women $(n=7617)$ were excluded because of an unknown treatment protocol or because they did not meet the inclusion criteria. Ki-67 results were missing if tissue was unavailable or if the tumor core was unsatisfactory after processing, staining, and imaging.

breast cancer by the time of the matched case's recurrence. ER status was defined as positive if $\geq 10 \%$ cells in tumor sections stained positive. Depending on the guidelines in Denmark at the time of diagnosis, $\mathrm{ER}^{+} / \mathrm{Tam}^{+}$women were assigned to tamoxifen therapy protocols of $>1$ year. Recurrent cases were defined as the occurrence of any (local, regional, contralateral or distant) breast cancer recurrence during follow-up time, as recorded in the DBCG Registry. Follow-up time started from 1 year after the primary surgery date until the date of the first breast cancer recurrence, death from any cause or emigration (assessed by DBCG registry), loss to follow-up, 10 years of follow-up or September 1, 2006 (i.e. end of study).

\section{Data Collection from Danish Registries}

Patient data were collected from the DBCG registry (date of diagnosis, UICC stage, tumor size, node status, histological grade, ER/progesterone receptor (PR) status, surgery type, chemotherapy, radiotherapy and hormonal therapy), and the Danish National Registry of Patients (comorbid diseases prevalent up to 10 years before breast cancer diagnosis).

\section{Tumor Tissue Microarray Construction}

Archived formalin-fixed, paraffin-embedded (FFPE) primary tumor tissue blocks from the cases and controls were collected from pathology departments of treating hospitals. A pathologist reviewed hematoxylin- and eosin (HE)stained tumor whole sections and identified regions of invasive carcinoma for sampling into TMAs. Using a TMA Master (3DHistech Ltd., Budapest, Hungary), cylindrical $1 \mathrm{~mm}$ diameter cores were sampled from each primary breast tumor (donor block) and re-embedded into recipient TMA paraffin blocks $(n=35)$ using standard procedures. ${ }^{27}$ One placental and two liver tissue cores were used as orientation markers in each TMA. From each patient sample, one to three representative tumor cores and one core with normal or tumor margin tissue were sampled, yielding a total of some 
5500 tumor tissue cores available for IHC staining. Patients' samples were not included in the TMAs if their tumor tissues could not be analyzed because of inadequate material $(n=226)$ (Figure 1).

\section{Immunohistochemistry for Ki-67}

We assessed Ki-67 expression in all 35 TMAs using IHC. Methods for tissue processing, antigen retrieval, antibody dilution and signal detection have been described, ${ }^{28,29}$ and are outlined in the Supplementary Material. Laboratory personnel were blinded to all clinical information, including ER/Tam status and case/control status.

\section{Automated Digital Image Assessment of Ki-67 Scores}

Ki-67 expression was evaluated using the fully automated VIS DIA VisioMorph system (Visiopharm ${ }^{\circledR}$, Hoersholm, Denmark), using similar image processing principles as described previously. ${ }^{16}$ In brief, all TMA-slides were scanned at 40x magnification using a Leica SCN400 slide scanner (Leica Biosystems, Wetzlar, Germany) and imported into the image analysis software program Visiopharm $^{\circledR}$, and a digital image was recorded of each core. We employed a customized analysis protocol package (APP) for Ki-67 quantification based on the same principles as before, with minor modifications and adjustments. Detection was based on both size and morphology of the nuclei; the tumor region of interest (ROI) was defined by outlining an ROI mask of tumor cells (Figure 2). Inside this mask of tumor cells, blue (negative) and brown (Ki-67- positive) nuclei were segmented using a Bayesian classifier. Pixels that contributed to Ki-67 positively stained nuclei were identified based on their brown DAB (3,3'diaminobenzidine) color deconvolution, whereas pixels of the negative class were identified by their blue HE stain. All cores were examined after the ROI had been defined, to be either accepted or edited (by manually removing any DCIS, TILs, artefacts, misclassifications, or empty cores and excluding unsuitable cores). All pixels of an image were then assigned a label for being either tumor cells expressing the Ki-67 (label 001/green), or negative tumor/normal cells (label 002/blue). Stromal cells were classified as background (label 003/red), and disregarded in the quantification (Table S1). Labelling of image pixels and subsequent classification of cells are shown in Table S1.

The Ki-67 score was then calculated automatically by the customized APP (Ki-67 score $=[$ (area of Ki-67positive tumor cells)/(area positive + negative tumor cells) $x$ 100]), using the areas of classified negative cells (i.e. blue nuclei) and classified positive cells (i.e. brown nuclei) (Figure 3). Again, any erroneously segmented areas were corrected manually. For some of the cores, the material was missing ( $\mathrm{n} \sim 350)$, tumor tissue was absent or less than 100 tumor cells were present ( $\mathrm{n} \sim 260)$, the $\mathrm{Ki}$ 67-staining was either too weak $(n \sim 45)$ or too excessive ( $n \sim 60$ ), or poor quality imaging or resolution $(n \sim 25)$, or displayed a combination of reasons; these were all excluded and the cores marked as missing. In total, $\mathrm{n}=149$ patients had insufficient or invalid tissue material on the tissue microarrays (TMAs) to be appropriately

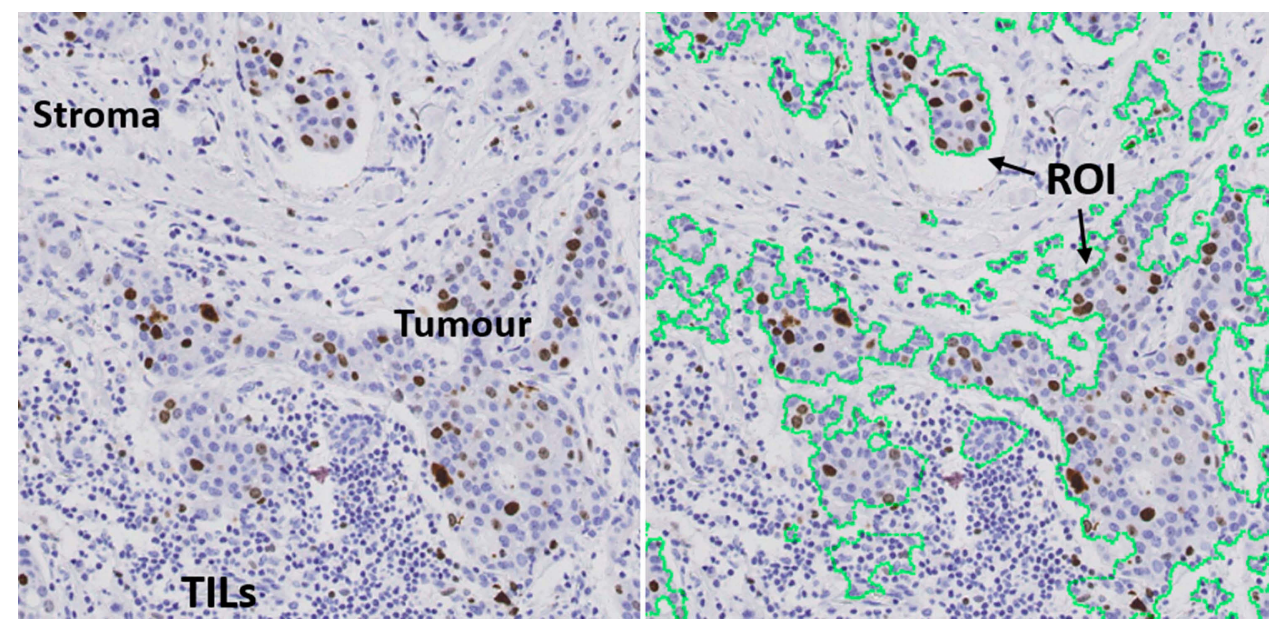

Figure 2 Tumor region of interest (ROI).

Notes: ROI (outlined in green) was defined semi-automatically in Visiopharm ${ }^{\circledR}$, based on both size and morphology of the cells. Stroma and TILs were disregarded by the customized APP.

Abbreviations: APP, analysis protocol package; TILs, tumor-infiltrating lymphocytes. 


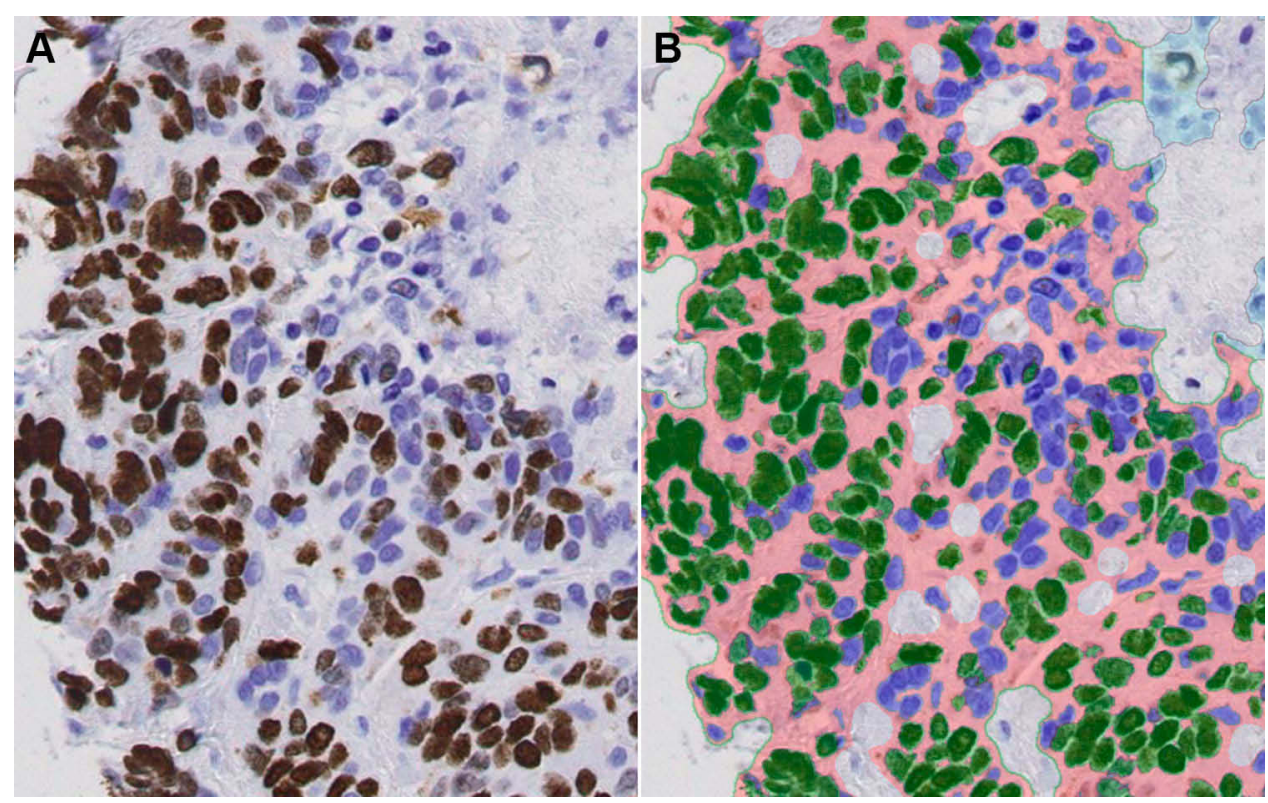

Figure 3 Representation of DIA scoring of Ki-67.

Notes: $(\mathbf{A})$ before, and (B) after, the customized algorithm was run in the Visiopharm ${ }^{\circledR}$ program. Ki-67-positive tumor cells were identified and scored in relation to the negative tumor cells: Ki-67 positively stained nuclei were identified based on their brown DAB staining, whereas negative cells were identified based on their blue H\&E stain. $\mathrm{Ki}-67$ score $=[($ area of Ki-67-positive tumor cells $) /($ area positive + negative tumor cells $) \times 100]$. DIA score in this particular core was calculated by the customized algorithm to be $61 \%$.

Abbreviation: DIA, digital image analysis.

scored, and were therefore excluded (examples of the exclusion criteria are shown in Figure S1). Finally, all cores were re-examined by two observers, adjusting the ROI or the labelling when appropriate, as well as excluding unsuitable cores. We set $15 \%$ as the limit of acceptance of intra-patient variability in the Ki-67 score (between the different cores from the same patient). In those cases in which this was exceeded, the cores were re-examined and accepted, edited further or discarded. For the great majority of the cores, the manual adjustments performed had little impact on the Ki-67 score. Larger discrepancies between the automated APP-generated and the edited Ki67 scores were double-checked. During the DIA-scoring, observers were blind to all clinical information, including $\mathrm{ER} / \mathrm{Tam}$, and case/control status.

\section{Ki-67 Score}

Out of 1456 individual patients with samples distributed in the 35 TMAs, 149 patients $(\sim 10 \%)$ were excluded during the DIA process (Figure 1), leaving a total of 1307 patient samples with one or more cores. More specifically, all three cores remained for 830 of the patients, two cores remained for 302 patients, and one core remained for 174 patients. Table S2 summarizes the TMA-DIA set-up. The proportion of tumor cells with a positive Ki-67 staining was noted as a continuous metric from $0 \%-100 \%$. For each patient between one and three cores were available, the final index being calculated as mean of the scores for the individual cores. The hotspot core was defined as the single core for each patient with the highest Ki-67 score. DIA-Ki-67 scores ranged from $0 \%-92 \%$. We created a dichotomous variable of Ki-67 expression in the primary breast tumors. A Ki-67 score above, or equal to, the study sample's median Ki-67 score (6.2\%) was considered positive and a score below the study sample's median Ki-67 score was considered to indicate no Ki-67 expression. In line with previous recommendations, ${ }^{23}$ we initially examined the distributions of Ki-67 with a $30 \%$ cut-off. This was, however, abandoned due to low numbers of patients above $30 \%$.

\section{Statistical Analyses}

All statistical analyses were conducted using SAS 9.4 (SAS Institute, Cary, NC), and within strata of the two patient groups $\left(\mathrm{ER}^{+} / \mathrm{Tam}^{+}\right.$and $\left.\mathrm{ER}^{-} / \mathrm{Tam}^{-}\right)$. Cases and controls were characterized using descriptive statistics. Distribution of patient clinicopathological factors was also characterized according to median $\mathrm{Ki}-67$ score. The data on $\mathrm{Ki}-67$ were not normally distributed and were therefore evaluated as a categorical variable. To estimate the matched odds ratios 
(ORs) between Ki-67 score and breast cancer recurrence, we applied logistic regression models adjusting for the matching factors. We adjusted for potential confounding variables using unconditional logistic regression models, including the matching factors, chemotherapy, type of surgery, receipt of radiation therapy, age category and comorbidity. We performed several sensitivity analyses: We reran the regression models also adjusting for grade. We stratified the analyses by time to recurrence, and by the receipt of chemotherapy. We also performed analyses using the median $\mathrm{Ki}-67$ score in $\mathrm{ER}^{+} / \mathrm{T}^{+}$patients, and the median $\mathrm{Ki}-67$ score in $\mathrm{ER}^{-} / \mathrm{Tam}^{-}$ patients.

\section{Results}

Descriptive and clinical characteristics of the study population differed little between the cases and their controls (Table 1). These characteristics were evenly distributed across Ki-67 score according to below (Table S3) or above (Table S4) the median Ki-67 score. DIA-Ki-67 scores were equally distributed across strata, both for the dichotomous value and the hotspot median. DIA-Ki-67 score was missing for 213 patients in the $\mathrm{ER}^{+} / \mathrm{Tam}^{+}$ group and for 118 patients in the $\mathrm{ER}^{-} / \mathrm{Tam}^{-}$. In the $\mathrm{ER}^{+} /$ $\mathrm{Tam}^{+}$group, the majority $(\sim 80 \%)$ of patients had a histological grade of either I or II. Conversely, for the $\mathrm{ER}^{-} / \mathrm{Tam}^{-}$group, the majority $(\sim 80 \%)$ had a histological grade of II or III. At the time of diagnosis, most patients had tumor stage II $\left(46 \% \mathrm{ER}^{+}\right.$and $\left.51 \% \mathrm{ER}^{-}\right)$or III $(52 \%$ $\mathrm{ER}^{+}$and $41 \% \mathrm{ER}^{-}$). More women were older than 55 years in the $\mathrm{ER}^{+} / \mathrm{Tam}^{+}$group compared with the $\mathrm{ER}^{-}$ group, and accordingly, more women were postmenopausal in the $\mathrm{ER}^{+} / \mathrm{Tam}^{+}$group, compared with the $\mathrm{ER}^{-} / \mathrm{Tam}^{-}$ group (94\% vs $60 \%)$. For quite a high number of patients, information was missing on grade, especially for the controls (around 25\%). These patterns are consistent with the selection of patients into tamoxifen treatment according to Danish guidelines in place at the time of the diagnoses.

For each ER/Tam group, estimates of the association between breast cancer recurrence and DIA-Ki-67 score are displayed in Table 2. DIA-Ki-67 score was not associated with increased risk of breast cancer recurrence, neither in the $\mathrm{ER}^{+} / \mathrm{Tam}^{+}(\mathrm{ORadj}=0.72,95 \% \mathrm{CI} 0.54,0.96)$, nor the $\mathrm{ER}^{-} / \mathrm{Tam}^{-}$groups (ORadj $=0.85,95 \%$ CI 0.54, 1.34). This was evident, both when assessing all available cores in each of the individual patients, or just the hotspot core (Table 2), using median DIA-Ki-67 score (6.2\%) as a cutoff. We also examined the distributions of the mean and hotspot DIA-Ki-67 scores across ER/Tam strata with a $30 \%$ cut-off, but this cut-off was abandoned due to very few patients $\geq 30 \%$ (Table S5), and since the median expression of $\mathrm{Ki}-67$ was close to the mean and hotspot values (Table S6). Furthermore, analyses using the median Ki-67 expression for each ER-stratum did not change the overall estimates, although for the $\mathrm{ER}^{-}$group with fewer patients, the adjusted ORs were higher but still with wide 95\% intervals (Table S7). The sensitivity analyses additionally adjusting for grade did not materially change the effect estimates (ORadj2 $=0.74,95 \%$ CI 0.52, 1.04) (Table S8); nor did the analysis stratifying by time to recurrence (Table S9), or by receipt of chemotherapy, although the $\mathrm{ER}^{-}$patients with chemo did have higher ORs (Tables S10 and S11).

\section{Discussion}

Our findings suggest that a high Ki-67-score is not associated with a greater risk of breast cancer recurrence, either in tamoxifen-treated patients, or in patients with $\mathrm{ER}^{-}$negative tumors. In fact, somewhat puzzling, our findings point to the opposite association, adding further complexity to the existing discussion concerning the association of $\mathrm{Ki}-67$ proliferation score with recurrence in tamoxifen-treated breast cancer patients. ${ }^{30}$

Our study has several strengths including the large number of patients $(n=1307)$, each with up to three representative tumor cores on the TMAs and the use of high-quality IHC assays. We had complete follow-up data from the DBCG clinical database, comprehensive data on patient, tumor and treatment characteristics. ${ }^{25,31}$ Additional strengths include the application of a technically advanced digital scoring system, for precisely assessing proliferation scores, specifically in tumor cells in the tissue cores.

Our study has some limitations. Although all patients were assigned tamoxifen for 1, 2 or 5 years, most patients who were assigned tamoxifen for only 1 or 2 years at diagnosis, took tamoxifen for a longer duration because of the emerging evidence of a survival benefit. ${ }^{24}$ In accordance with the guidelines at the time, the threshold for ER positivity was $\geq 10 \%$ positively stained cells, whereas nowadays, with more sensitive detection methods, a $1 \%$ threshold is used. In addition, the TMAs of the Jutland Breast Cancer Biobank were not constructed specifically for assessing $\mathrm{Ki}-67$; therefore, although the region of sampling was within the tumor area, and up to three large cores (diameter $1 \mathrm{~mm}$ ) were taken from each tumor, the cores were not selected from the invasive tumor front only. Ki-67 staining can be heterogeneous in 
Table I Patient and Clinical Characteristics for Cases and Controls of the Jutland Breast Cancer Recurrence Biobank

\begin{tabular}{|c|c|c|c|c|c|c|c|c|}
\hline \multirow{2}{*}{$\begin{array}{l}\text { Patient Characteristics } \\
\text { DIA Ki-67 score }\end{array}$} & \multicolumn{4}{|c|}{$\begin{array}{l}\mathrm{ER}^{+} / \mathrm{Tam}^{+} \\
\text {No. }(\%)\end{array}$} & \multicolumn{4}{|c|}{$\begin{array}{l}\mathrm{ER}^{-} / \mathrm{Tam}^{-} \\
\text {No. }(\%)\end{array}$} \\
\hline & \multicolumn{2}{|c|}{$\begin{array}{l}\text { Recurrent Cases } \\
n=541\end{array}$} & \multicolumn{2}{|c|}{$\begin{array}{l}\text { Controls } \\
n=541\end{array}$} & \multicolumn{2}{|c|}{$\begin{array}{l}\text { Recurrent Cases } \\
n=300\end{array}$} & \multicolumn{2}{|c|}{$\begin{array}{l}\text { Controls } \\
n=300\end{array}$} \\
\hline $\begin{array}{l}\text { DIA Ki-67 score } \\
<\text { Median } \\
\text { Median or above } \\
\text { Missing }\end{array}$ & $\begin{array}{l}245 \\
188 \\
108\end{array}$ & $\begin{array}{l}(57) \\
(43)\end{array}$ & $\begin{array}{l}276 \\
160 \\
105\end{array}$ & $\begin{array}{l}(63) \\
(37)\end{array}$ & $\begin{array}{l}76 \\
170 \\
54\end{array}$ & $\begin{array}{l}(31) \\
(69)\end{array}$ & $\begin{array}{l}79 \\
157 \\
64\end{array}$ & $\begin{array}{l}\text { (33) } \\
\text { (67) }\end{array}$ \\
\hline $\begin{array}{l}\text { Hotspot } \\
<\text { Median } \\
\text { Median or above } \\
\text { Missing }\end{array}$ & $\begin{array}{l}243 \\
190 \\
108\end{array}$ & $\begin{array}{l}(56) \\
(44)\end{array}$ & $\begin{array}{l}272 \\
164 \\
105\end{array}$ & $\begin{array}{l}(62) \\
(38)\end{array}$ & $\begin{array}{l}80 \\
166 \\
54\end{array}$ & $\begin{array}{l}(33) \\
(67)\end{array}$ & $\begin{array}{l}80 \\
156 \\
64\end{array}$ & $\begin{array}{l}\text { (34) } \\
\text { (66) }\end{array}$ \\
\hline $\begin{array}{l}\text { Year of diagnosis } \\
\text { 1985-1993 } \\
1994-1996 \\
1997-200 \mid\end{array}$ & $\begin{array}{l}235 \\
113 \\
193\end{array}$ & $\begin{array}{l}(43) \\
(2 I) \\
(36)\end{array}$ & $\begin{array}{l}234 \\
112 \\
195\end{array}$ & $\begin{array}{l}(43) \\
(2 I) \\
(36)\end{array}$ & $\begin{array}{l}107 \\
81 \\
112\end{array}$ & $\begin{array}{l}(36) \\
(27) \\
(37)\end{array}$ & $\begin{array}{l}100 \\
83 \\
117\end{array}$ & $\begin{array}{l}(33) \\
(28) \\
(39)\end{array}$ \\
\hline $\begin{array}{l}\text { Age at diagnosis } \\
\text { 35-44 } \\
45-54 \\
55-64 \\
65-69\end{array}$ & $\begin{array}{l}16 \\
116 \\
286 \\
123\end{array}$ & $\begin{array}{l}(3.0) \\
(21) \\
(53) \\
(23)\end{array}$ & $\begin{array}{l}13 \\
111 \\
281 \\
136\end{array}$ & $\begin{array}{l}(2.4) \\
(21) \\
(52) \\
(25)\end{array}$ & $\begin{array}{l}68 \\
120 \\
82 \\
30\end{array}$ & $\begin{array}{l}(23) \\
(40) \\
(27) \\
(10)\end{array}$ & $\begin{array}{l}58 \\
113 \\
86 \\
43\end{array}$ & $\begin{array}{l}(19) \\
(38) \\
(29) \\
(14)\end{array}$ \\
\hline $\begin{array}{c}\text { Menopausal status } \\
\text { Premenopausal } \\
\text { Postmenopausal }\end{array}$ & $\begin{array}{l}34 \\
507\end{array}$ & $\begin{array}{l}(6.3) \\
(94)\end{array}$ & $\begin{array}{l}34 \\
507\end{array}$ & $\begin{array}{l}(6.3) \\
(94)\end{array}$ & $\begin{array}{l}121 \\
179\end{array}$ & $\begin{array}{l}(40) \\
(60)\end{array}$ & $\begin{array}{l}121 \\
179\end{array}$ & $\begin{array}{l}(40) \\
(60)\end{array}$ \\
\hline $\begin{array}{l}\text { UICC tumour stage } \\
\text { I } \\
\text { II } \\
\text { III }\end{array}$ & $\begin{array}{l}9 \\
250 \\
282\end{array}$ & $\begin{array}{l}(1.7) \\
(46) \\
(52)\end{array}$ & $\begin{array}{l}9 \\
250 \\
282\end{array}$ & $\begin{array}{l}(1.7) \\
(46) \\
(52)\end{array}$ & $\begin{array}{l}25 \\
153 \\
122\end{array}$ & $\begin{array}{l}(8.3) \\
(5 I) \\
(4 I)\end{array}$ & $\begin{array}{l}25 \\
153 \\
122\end{array}$ & $\begin{array}{l}(8.3) \\
(5 I) \\
(4 I)\end{array}$ \\
\hline $\begin{array}{l}\text { Histological grade } \\
\text { I } \\
\text { II } \\
\text { III } \\
\text { Missing }\end{array}$ & $\begin{array}{l}108 \\
234 \\
92 \\
107\end{array}$ & $\begin{array}{l}(25) \\
(54) \\
(21)\end{array}$ & $\begin{array}{l}144 \\
215 \\
57 \\
125\end{array}$ & $\begin{array}{l}(35) \\
(52) \\
(14)\end{array}$ & $\begin{array}{l}27 \\
125 \\
103 \\
45\end{array}$ & $\begin{array}{l}(1 \mathrm{I}) \\
(49) \\
(40)\end{array}$ & $\begin{array}{l}23 \\
98 \\
106 \\
73\end{array}$ & $\begin{array}{l}(10) \\
(43) \\
(47)\end{array}$ \\
\hline $\begin{array}{l}\text { Surgery type } \\
\text { Breast-conserving } \\
\text { Mastectomy } \\
\text { Missing }\end{array}$ & $\begin{array}{l}58 \\
483 \\
0\end{array}$ & $\begin{array}{l}(11) \\
(89)\end{array}$ & $\begin{array}{l}71 \\
470\end{array}$ & $\begin{array}{l}(13) \\
(87) \\
0\end{array}$ & $\begin{array}{l}47 \\
252 \\
1\end{array}$ & $\begin{array}{l}(16) \\
(84)\end{array}$ & $\begin{array}{l}56 \\
244 \\
0\end{array}$ & $\begin{array}{l}(19) \\
(81)\end{array}$ \\
\hline $\begin{array}{l}\text { Systemic adjuvant chemotherapy } \\
\text { Yes } \\
\text { No }\end{array}$ & $\begin{array}{l}70 \\
471\end{array}$ & $\begin{array}{l}(13) \\
(87)\end{array}$ & $\begin{array}{l}65 \\
476\end{array}$ & $\begin{array}{l}(12) \\
(88)\end{array}$ & $\begin{array}{l}248 \\
52\end{array}$ & $\begin{array}{l}(83) \\
(17)\end{array}$ & $\begin{array}{l}188 \\
112\end{array}$ & $\begin{array}{l}(63) \\
(37)\end{array}$ \\
\hline $\begin{array}{l}\text { Radiation therapy } \\
\text { Yes } \\
\text { No } \\
\text { Missing }\end{array}$ & $\begin{array}{l}183 \\
358 \\
0\end{array}$ & $\begin{array}{l}(34) \\
(66)\end{array}$ & $\begin{array}{l}191 \\
350 \\
0\end{array}$ & $\begin{array}{l}(35) \\
(65)\end{array}$ & $\begin{array}{l}128 \\
166 \\
6\end{array}$ & $\begin{array}{l}(47) \\
(56)\end{array}$ & $\begin{array}{l}123 \\
137 \\
40\end{array}$ & $\begin{array}{l}(47) \\
(53)\end{array}$ \\
\hline $\begin{array}{l}\text { Tamoxifen protocol, years } \\
1 \\
2 \\
5\end{array}$ & $\begin{array}{l}257 \\
98 \\
186\end{array}$ & $\begin{array}{l}(48) \\
(18) \\
(34)\end{array}$ & $\begin{array}{l}26 \mid \\
92 \\
188\end{array}$ & $\begin{array}{l}(48) \\
(17) \\
(35)\end{array}$ & $\begin{array}{l}- \\
-\end{array}$ & & $\begin{array}{l}- \\
-\end{array}$ & \\
\hline
\end{tabular}

Abbreviations: ER, oestrogen receptor; Tam, tamoxifen; UICC, Union for International Cancer Control. 
Table 2 Associations Between Ki-67 Expression and Breast Cancer Recurrence Within ER/Tam Groups

\begin{tabular}{|c|c|c|c|c|c|c|}
\hline \multirow{2}{*}{$\begin{array}{l}\text { Ki-67 } \\
\text { Expression }\end{array}$} & \multicolumn{3}{|l|}{$\mathrm{ER}^{+} / \mathrm{Tam}^{+}$} & \multicolumn{3}{|l|}{$\mathrm{ER}^{-} / \mathrm{Tam}^{-}$} \\
\hline & $\begin{array}{l}\text { Cases/ } \\
\text { Controls (n) }\end{array}$ & $\begin{array}{l}\text { Matched OR } \\
(95 \% \mathrm{Cl})\end{array}$ & $\begin{array}{l}\text { Adjusted } O^{a} \\
(95 \% \mathrm{Cl})\end{array}$ & $\begin{array}{l}\text { Cases/ } \\
\text { Controls }\end{array}$ & $\begin{array}{l}\text { Matched OR } \\
(95 \% \mathrm{Cl})\end{array}$ & $\begin{array}{l}\text { Adjusted } O^{\mathrm{a}} \\
(95 \% \mathrm{CI})\end{array}$ \\
\hline $\begin{array}{l}\text { All cores } \\
\quad<\text { median } \\
\geq \text { median }\end{array}$ & $\begin{array}{l}245 / 276 \\
188 / 160\end{array}$ & $\begin{array}{l}\text { I } \\
0.74(0.56,0.98)\end{array}$ & $\begin{array}{l}\text { I } \\
0.72(0.54,0.96)\end{array}$ & $\begin{array}{l}76 / 79 \\
170 / 157\end{array}$ & $\begin{array}{l}\text { I } \\
0.87(0.59,1.30)\end{array}$ & $\begin{array}{l}\text { I } \\
0.85(0.54, I .34)\end{array}$ \\
\hline $\begin{array}{l}\text { Hotspot } \\
\quad<\text { median } \\
\geq \text { median }\end{array}$ & $\begin{array}{l}243 / 272 \\
190 / 164\end{array}$ & $\begin{array}{l}\text { I } \\
0.75(0.57,1.00)\end{array}$ & $\begin{array}{l}\text { I } \\
0.73(0.55,0.98)\end{array}$ & $\begin{array}{l}80 / 80 \\
166 / 156\end{array}$ & $0.92(0.62,1.3)$ & $0.86(0.55, I .35)$ \\
\hline
\end{tabular}

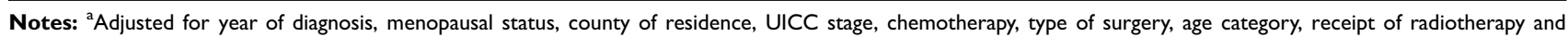
comorbidity.

Abbreviations: $\mathrm{OR}$, odds ratio; $\mathrm{Cl}$, confidence interval.

breast cancers, and correct sampling is therefore important. The periphery of the tumor is most often the area with the highest percentage of Ki-67-positive cells i.e. the socalled hotspot areas. ${ }^{16,32}$ As a consequence, our analysis might misclassify Ki-67 scores compared with scores obtained from the invasive front of the tumor alone, as is the currently recommended protocol for performing Ki-67 assays in breast cancer. ${ }^{23}$ The International Ki67 in Breast Cancer Working Group recommends Ki-67 scoring should be counted in at least 500 tumor cells, a higher number than the cell-limit of 100 we have applied herein. ${ }^{33}$ In addition, our reported median Ki-67 of $6.5 \%$ is low compared to other studies. ${ }^{34}$ However, in a previous report by co-authors, the reported DIA-Ki-67 threshold was $6.5 \%$, this being the most robust and strongest prognosticator; which is in concordance with the present study. ${ }^{16}$ Followup started 1 year after the time of diagnosis, therefore any recurrences within the first year are not recorded. Early recurrences are often associated with highly proliferating tumors, ${ }^{35}$ which would bias towards the null. The DBCG follow-up program continues up to 10 years after diagnosis. Consequently, recurrences that occur later are not recorded in this study. We did not have access to tumor biopsies of recurrences, and were therefore unable to evaluate any change in Ki-67 levels over time.

Previous studies on the association of Ki-67 score and response to tamoxifen therapy are conflicting. ${ }^{36}$ Yerushalmi and colleagues examined the prognostic and predictive potential of Ki- 67 scores in breast cancer in a review of 22 studies. They concluded that, based on the existing literature, no robust evidence could be found recommending $\mathrm{Ki}-67$ as a tool to identify patients who would benefit from a specific endocrine treatment. ${ }^{36}$ The Breast International Group
(BIG)-1 98 trials showed that the aromatase inhibitor letrozole resulted in greater treatment benefit compared with tamoxifen treatment for patients with a high Ki-67 labelling index. ${ }^{37}$ However, in a small study of 70 post-menopausal tamoxifen-treated breast cancer patients, high (cut-off 30\%) Ki-67 was associated with tamoxifen resistance and poor prognosis, in terms of recurrence and survival. ${ }^{38}$ Furthermore, Ki-67 score was higher among patients who developed early relapse (within the first 24 months) after starting tamoxifen, yet there was no difference in relapse risk for those with tumors expressing high versus low Ki$67 .{ }^{38}$ In a more recent study, Beelen et al tested the expression of Ki-67 score in a cohort of 563 post-menopausal women with $\mathrm{ER}^{+}$breast cancers, and found that patients with high Ki-67 counts did benefit from adjuvant tamoxifen. ${ }^{39}$ However, in their study, high Ki-67 was defined as $\geq 5 \%$ expression. Moreover, tamoxifen efficacy was reduced in patients whose tumors had a high mitotic count, but in patients with low mitotic count, tamoxifen was of benefit. At the same time, they observed that patients with tumors with a high mitotic count could still have low tumor Ki-67 scores, and that mitotic count outperformed Ki-67 with regard to prediction of the benefit of endocrine treatment. ${ }^{39}$ Of note, both these studies included postmenopausal patients. Our study population consisted of mostly postmenopausal, but also some premenopausal patients. Others have examined the potential effect of pre-surgical short-term endocrine treatment on Ki-67 score. Dowsett et al studied 158 patients with $\mathrm{HR}^{+}$primary disease, and correlated the change in $\mathrm{Ki}-67$ score in tumor biopsies taken before and 2 weeks after, treatment with anastrozole and/or tamoxifen. They reported that only the change in Ki-67 level was associated with treatment benefit, whereas the absolute level of Ki-67 
expression at baseline was not significantly associated with recurrence-free survival. ${ }^{19}$ Similarly, Cohen et al found a 40\% mean decrease in Ki-67 scores after only 7 days of presurgical treatment and suggested using change in the Ki-67 index in future endocrine treatment trials. ${ }^{40}$

Taken together, these studies demonstrate the complexity that exists when trying to assess tumor cell proliferation and its potential effects on tamoxifen treatment. The prognostic information associated with the Ki-67 analysis may be limited to very high or very low index scores. ${ }^{21}$ There is no consensus regarding the definition of high/low Ki-67 proliferation indices. For instance, the reported optimal cut-off value of Ki-67 to separate Luminal A and Luminal B breast cancers, or low-risk from high-risk patients, varies substantially across studies (i.e. from $10 \%$ to $30 \%)^{17,38,41,42}$

Muftah and co-workers analyzed Ki-67 scores in breast cancer, comparing whole tissue sections with TMAs constructed with a single $0.6 \mathrm{~mm}$ diameter core from each patient sample. They conclude that Ki-67 expression in breast cancer can be evaluated in TMAs, as long as the allowance is made for the substantial heterogeneity of Ki67 expression. $^{42}$ In comparison with Muftah and coworkers' study, and other published studies, our TMAs were constructed using up to three tumor cores, each $1 \mathrm{~mm}$ in diameter, thus including in the TMAs considerably larger areas of tumor tissue for assessment. This was done in order to improve the representativeness of the TMAs, and we believe it enhanced the precision of our study. The amount of tumor tissue included in our TMAs was considerably greater than that recommended as a minimum by Khoury et al, who conclude that either three $0.6-\mathrm{mm}$ cores or a single $1.0-\mathrm{mm}$ core was adequate to be representative of whole tissue sections. ${ }^{43}$

We hypothesized that DIA of Ki-67 score could be used to efficiently evaluate proliferation in breast cancer tumors, and that high DIA-Ki-67 scores might be associated with response to tamoxifen. As we have shown, the DIA set-up and the automated DIA-Ki-67 scoring were successful. However, it is important to emphasize that in practice, pre-analytical variables (e.g. fixation, cutting, staining issues, region of sampling, scanning, inclusion/ exclusion criteria) can have substantial effects on the outcome of automated scoring. ${ }^{44}$

In our study, we also examined the $\mathrm{Ki}-67$-score in $\mathrm{ER}^{-}$ tumors, and did not observe any substantial differences in this when comparing recurrent cases and controls. Our results are in line with the variability seen in other studies, ${ }^{45}$ and underline the complexity and well-known challenges of using the Ki-67 index as a biomarker in clinical decision-making. ${ }^{46,47}$

\section{Conclusion}

In summary, we found that the Ki-67 index (as measured digitally by image analysis in TMAs) was not associated with increased risk of recurrence among tamoxifen-treated $\mathrm{ER}^{+}$breast cancer or $\mathrm{ER}^{-}$breast cancer patients. Overall, our findings do not support an increased risk of recurrence associated with Ki-67 expression. Future work should aim to standardize and define a clinically relevant Ki-67 threshold before it is used for clinical decision-making in tamoxifen-treated breast cancer patients.

\section{Abbreviations}

APP, analysis protocol package, DIA, digital image analysis; $\mathrm{ER}^{+}$, estrogen receptor positive; $\mathrm{ER}^{-}$, estrogen receptor negative; IHC, immunohistochemistry; ROI, region of interest; Tam, tamoxifen; TMA, tissue microarray.

\section{Ethics Approval and Informed Consent}

This study was approved by the Norwegian National Research Ethics Committees/Regional Committees for Medical and Health Research Ethics (REC) West (REC number 23216), and the Regional Committee on Biomedical Research Ethics of Denmark's Central Region (Record No. 1-10-72-16-15). According to Danish law, registry-based research is exempt from informed consent requirements.

\section{Acknowledgments}

We thank Anders Kjærsgaard (PhD, Aarhus University Hospital) for excellent help with the statistical analyses. We thank Marit Nordhus and Melinda Lillesand (Department of Pathology, Stavanger University Hospital) for their thorough work on the IHC staining and excellent technical assistance. We thank Emma Rewcastle (Department of Pathology, Stavanger University Hospital) for contributing to language editing. Furthermore, the authors thank the Danish Breast Cancer Group for access to its registry data.

\section{Author Contributions}

All authors made substantial contributions to conception and design, acquisition of data, or analysis and interpretation of data; took part in drafting the article or revising it 
critically for important intellectual content; gave final approval of the version to be published; and agree to be accountable for all aspects of the work.

\section{Funding}

This work was supported by multiple agency grants; Kristin Jonsdottir and Nina Gran Egeland obtained grants from Folke Hermansen Foundation (2013, 2014, and 2019), Norway. This project was additionally supported by funding from the National Cancer Institute (R01 CA118708 and R01 CA166825) awarded to Timothy Lash, the Danish Cancer Society (DP06117) awarded to Stephen Hamilton-Dutoit; the Lundbeck Foundation (R167-2013-15861) and the Danish Cancer Research Foundation awarded to Deirdre Cronin-Fenton, and the Danish Medical Research Council (DOK 1158869) awarded to Timothy Lash.

\section{Disclosure}

Timothy L Lash reports receiving personal fees from Amgen, outside the submitted work. The authors report no other conflicts of interest in this work.

\section{References}

1. Pan H, Gray R, Braybrooke J, et al. 20-year risks of breast-cancer recurrence after stopping endocrine therapy at 5 years. $N$ Engl J Med. 2017;377(19):1836-1846. doi:10.1056/NEJMoa1701830

2. Colleoni M, Sun Z, Price KN, et al. Annual hazard rates of recurrence for breast cancer during 24 years of follow-up: results from the international breast cancer study group trials I to V. J clin oncol. 2016;34 (9):927-935. doi:10.1200/JCO.2015.62.3504

3. Early Breast Cancer Trialists' Collaborative G, Davies C, Godwin J, et al. Relevance of breast cancer hormone receptors and other factors to the efficacy of adjuvant tamoxifen: patient-level meta-analysis of randomised trials. Lancet. 2011;378(9793):771-784.

4. Brzozowski AM, Pike AC, Dauter Z, et al. Molecular basis of agonism and antagonism in the oestrogen receptor. Nature. 1997;389 (6652):753-758. doi:10.1038/39645

5. Manavathi B, Dey O, Gajulapalli VNR, Bhatia RS, Bugide S, Kumar R. Derailed estrogen signaling and breast cancer: an authentic couple. Endocr Rev. 2013;34(1):1-32. doi:10.1210/er.2011-1057

6. Davies C, Pan H, Godwin J, et al. Long-term effects of continuing adjuvant tamoxifen to 10 years versus stopping at 5 years after diagnosis of oestrogen receptor-positive breast cancer: ATLAS, a randomised trial. The Lancet. 2013;381(9869):805-816. doi:10. 1016/S0140-6736(12)61963-1

7. Riggins RB, Schrecengost RS, Guerrero MS, Bouton AH. Pathways to tamoxifen resistance. Cancer Lett. 2007;256(1):1-24. doi:10.1016/j. canlet.2007.03.016

8. Haque MM, Desai KV. Pathways to endocrine therapy resistance in breast cancer. Front Endocrinol (Lausanne). 2019;10:573. doi:10.33 89/fendo.2019.00573

9. Musgrove EA, Sutherland RL. Biological determinants of endocrine resistance in breast cancer. Nat Rev Cancer. 2009;9(9):631-643. doi: $10.1038 / \mathrm{nrc} 2713$
10. Hershman DL, Kushi LH, Shao T, et al. Early discontinuation and nonadherence to adjuvant hormonal therapy in a cohort of 8,769 early-stage breast cancer patients. J clin oncol. 2010;28(27):41 20-4128. doi:10.1200/JCO.2009.25.9655

11. Owusu C, Buist DS, Field TS, et al. Predictors of tamoxifen discontinuation among older women with estrogen receptor-positive breast cancer. $J$ clin oncol. 2008;26(4):549-555. doi:10.1200/JCO.2006.10.1022

12. Helland T, Hagen KB, Haugstøyl ME, et al. Drug monitoring of tamoxifen metabolites predicts vaginal dryness and verifies a low discontinuation rate from the Norwegian Prescription Database. Breast Cancer Res Treat. 2019;177(1):185-195. doi:10.1007/s105 49-019-05294-w

13. Inwald EC, Klinkhammer-Schalke M, Hofstadter F, et al. Ki-67 is a prognostic parameter in breast cancer patients: results of a large population-based cohort of a cancer registry. Breast Cancer Res Treat. 2013;139(2):539-552. doi:10.1007/s10549-013-2560-8

14. Soliman NA, Yussif SM. Ki-67 as a prognostic marker according to breast cancer molecular subtype. Cancer Biol Med. 2016;13 (4):496-504. doi:10.20892/j.issn.2095-3941.2016.0066

15. Nishimura R, Osako T, Okumura Y, Hayashi M, Toyozumi Y, Arima N. Ki-67 as a prognostic marker according to breast cancer subtype and a predictor of recurrence time in primary breast cancer. Exp Ther Med. 2010;1(5):747-754. doi:10.3892/etm.2010.133

16. Gudlaugsson E, Skaland I, Janssen EA, et al. Comparison of the effect of different techniques for measurement of Ki67 proliferation on reproducibility and prognosis prediction accuracy in breast cancer. Histopathology. 2012;61(6):1134-1144. doi:10.1111/j.1365-2559.20 12.04329.x

17. Cheang MC, Chia SK, Voduc D, et al. Ki67 index, HER2 status, and prognosis of patients with luminal B breast cancer. $J$ Natl Cancer Inst. 2009;101(10):736-750. doi:10.1093/jnci/djp082

18. Arima N, Nishimura R, Osako T, et al. Ki-67 index value and progesterone receptor status can predict prognosis and suitable treatment in node-negative breast cancer patients with estrogen receptor-positive and HER2-negative tumors. Oncol Lett. 2019;17 (1):616-622. doi:10.3892/ol.2018.9633

19. Dowsett M, Smith IE, Ebbs SR, et al. Prognostic value of Ki67 expression after short-term presurgical endocrine therapy for primary breast cancer. J Natl Cancer Inst. 2007;99(2):167-170. doi:10.1093/ jnci/djk020

20. Kim C, Tang G, Pogue-Geile KL, et al. Estrogen receptor (ESR1) mRNA expression and benefit from tamoxifen in the treatment and prevention of estrogen receptor-positive breast cancer. $J$ clin oncol. 2011;29(31):4160-4167. doi:10.1200/JCO.2010.32.9615

21. Jirstrom K, Ryden L, Anagnostaki L, et al. Pathology parameters and adjuvant tamoxifen response in a randomised premenopausal breast cancer trial. J Clin Pathol. 2005;58(11):1135-1142. doi:10.1136/ jcp.2005.027185

22. Leung SCY, Nielsen TO, Zabaglo L, et al. Analytical validation of a standardized scoring protocol for Ki67: Phase 3 of an international multicenter collaboration. NPJ Breast Cancer. 2016;2:16014. doi:10.1038/npjbcancer.2016.14

23. NBCG NBCG. Nasjonalt handlingsprogram med retningslinjer for diagnostikk, behandling og oppfølging av pasienter med brystkreft. In: The Norwegian Directorate of Health, editor. Nasjonalt Handlingsprogram Med Retningslinjer for Diagnostikk, Behandling og Oppfølging av Pasienter Med Brystkreft. Vol. 10. The Norwegian Directorate of Health; 2017. Available from: https://nbcgblog.files. wordpress.com/2018/01/nasjonalt_handlingsprog_brystkreft_10versjon_is-2669.pdf. Accessed June 22, 2020.

24. Lash TL, Cronin-Fenton D, Ahern TP, et al. CYP2D6 inhibition and breast cancer recurrence in a population-based study in Denmark. J Natl Cancer Inst. 2011;103(6):489-500. doi:10.1093/jnci/djr010

25. Christiansen P, Ejlertsen B, Jensen MB, Mouridsen H. Danish breast cancer cooperative group. Clin Epidemiol. 2016;8:445-449. doi:10. 2147/CLEP.S99457 
26. Rothman KJ, Greenland S, Lash TL. Modern epidemiology - casecontrol studies. In: Modern Epidemiology. 3 ed ed. Philadelhia PA, USA: Lippincott Williams \& Wilkins; 2008:124.

27. Kononen J, Bubendorf L, Kallioniemi A, et al. Tissue microarrays for high-throughput molecular profiling of tumor specimens. Nat Med. 1998;4(7):844-847. doi:10.1038/nm0798-844

28. Skaland I, Janssen EA, Gudlaugsson E, et al. Validating the prognostic value of proliferation measured by Phosphohistone H3 (PPH3) in invasive lymph node-negative breast cancer patients less than 71 years of age. Breast Cancer Res Treat. 2009;114(1):39-45. doi:10.10 07/s10549-008-9980-x

29. Gudlaugsson E, Klos J, Skaland I, et al. Prognostic comparison of the proliferation markers (mitotic activity index, phosphohistone H3, Ki67), steroid receptors, HER2, high molecular weight cytokeratins and classical prognostic factors in $\mathrm{T}(1)(-)(2) \mathrm{N}(0) \mathrm{M}(0)$ breast cancer. Polish J Pathol. 2013;64(1):1-8. doi:10.5114/pjp.2013.34596

30. Regan MM, Pagani O, Francis PA, et al. Predictive value and clinical utility of centrally assessed ER, PgR, and Ki-67 to select adjuvant endocrine therapy for premenopausal women with hormone receptor-positive, HER2-negative early breast cancer: TEXT and SOFT trials. Breast Cancer Res Treat. 2015;154(2):275-286. doi:10.1007/s10549-015-3612-z

31. Moller S, Jensen MB, Ejlertsen B, et al. The clinical database and the treatment guidelines of the Danish Breast Cancer Cooperative Group (DBCG); its 30-years experience and future promise. Acta Oncol (Madr). 2008;47(4):506-524. doi:10.1080/02841860802059259

32. Stalhammar G, Robertson S, Wedlund L, et al. Digital image analysis of Ki67 in hot spots is superior to both manual Ki67 and mitotic counts in breast cancer. Histopathology. 2018;72(6):974-989. doi: $10.1111 /$ his. 13452

33. Dowsett M, Nielsen TO, A'Hern R, et al. Assessment of Ki67 in breast cancer: recommendations from the International Ki67 in Breast Cancer working group. J Natl Cancer Inst. 2011;103(22):1656-1664. doi:10.1093/jnci/djr393

34. Wang M, McLaren S, Jeyathevan R, et al. Laboratory validation studies in Ki-67 digital image analysis of breast carcinoma: a pathway to routine quality assurance. Pathology. 2019;51(3): 246-252. doi:10.1016/j.pathol.2018.12.416

35. Ribelles N, Perez-Villa L, Jerez JM, et al. Pattern of recurrence of early breast cancer is different according to intrinsic subtype and proliferation index. Breast Cancer Res. 2013;15(5):R98. doi:10.11 $86 /$ bcr3559

36. Yerushalmi R, Woods R, Ravdin PM, Hayes MM, Gelmon KA. Ki67 in breast cancer: prognostic and predictive potential. Lancet Oncol. 2010;11(2):174-183. doi:10.1016/S1470-2045(09)70262-1
37. Viale G, Giobbie-Hurder A, Regan MM, et al. Prognostic and predictive value of centrally reviewed $\mathrm{Ki}-67$ labeling index in postmenopausal women with endocrine-responsive breast cancer: results from Breast International Group Trial 1-98 comparing adjuvant tamoxifen with letrozole. J clin oncol. 2008;26(34):5569-5575. doi:10.1200/JCO.2008.17.0829

38. Elzawahry HM, Saber MM, Mokhtar NM, Zeeneldin AA, Ismail YM, Alieldin NH. Role of Ki67 in predicting resistance to adjuvant tamoxifen in postmenopausal breast cancer patients. $J$ Egypt Natl Canc Inst. 2013;25(4):181-191. doi:10.1016/j.jnci.2013.02.001

39. Beelen K, Opdam M, Severson T, et al. Mitotic count can predict tamoxifen benefit in postmenopausal breast cancer patients while Ki67 score cannot. BMC Cancer. 2018;18(1):761. doi:10.1186/ s12885-018-4516-1

40. Cohen AL, Factor RE, Mooney K, et al. POWERPIINC (PreOperative Window of Endocrine TheRapy Provides Information to Increase Compliance) trial: changes in tumor proliferation index and quality of life with 7 days of preoperative tamoxifen. Breast. 2017;31:219-223. doi:10.1016/j.breast.2016.11.016

41. Acs B, Pelekanou V, Bai Y, et al. Ki67 reproducibility using digital image analysis: an inter-platform and inter-operator study. Lab Invest. 2019;99(1):107-117. doi:10.1038/s41374-018-0123-7

42. Muftah AA, Aleskandarany MA, Al-Kaabi MM, et al. Ki67 expression in invasive breast cancer: the use of tissue microarrays compared with whole tissue sections. Breast Cancer Res Treat. 2017;164 (2):341-348. doi:10.1007/s10549-017-4270-0

43. Khoury T, Zirpoli G, Cohen SM, et al. Ki-67 expression in breast cancer tissue microarrays: assessing tumor heterogeneity, concordance with full section, and scoring methods. Am J Clin Pathol. 2017;148(2):108-118. doi:10.1093/ajcp/aqx053

44. Tadrous PJ. On the concept of objectivity in digital image analysis in pathology. Pathology. 2010;42(3):207-211. doi:10.3109/003130210 03641758

45. Robertson S, Stalhammar G, Darai-Ramqvist E, et al. Prognostic value of $\mathrm{Ki} 67$ analysed by cytology or histology in primary breast cancer. J Clin Pathol. 2018;71(9):787-794. doi:10.1136/jclinpath2017-204976

46. Raap M, Liessem S, Ruschoff J, et al. Quality assurance trials for Ki67 assessment in pathology. Virchows Archiv. 2017;471(4):50 1-508. doi:10.1007/s00428-017-2142-y

47. Penault-Llorca F, Radosevic-Robin N. Ki67 assessment in breast cancer: an update. Pathology. 2017;49(2):166-171. doi:10.1016/j. pathol.2016.11.006
Clinical Epidemiology

\section{Publish your work in this journal}

Clinical Epidemiology is an international, peer-reviewed, open access, online journal focusing on disease and drug epidemiology, identification of risk factors and screening procedures to develop optimal preventative initiatives and programs. Specific topics include: diagnosis, prognosis, treatment, screening, prevention, risk factor modification,

Submit your manuscript here: https://www.dovepress.com/clinical-epidemiology-journal systematic reviews, risk \& safety of medical interventions, epidemiology \& biostatistical methods, and evaluation of guidelines, translational medicine, health policies \& economic evaluations. The manuscript management system is completely online and includes a very quick and fair peer-review system, which is all easy to use. 